\title{
Grapes from the geographical areas of the Black Sea: Agroclimatic growing conditions and evaluation of stable isotopes compositions in scientific study
}

\author{
Alexander Kolesnov ${ }^{1}$ and Natalya Agafonova ${ }^{2}$ \\ ${ }^{1}$ Research Laboratory of Food Quality \& Technology (PNIL), RUDN University, 117198 Moscow, Russian Federation \\ ${ }^{2}$ National Research Institute of Viticulture and Winemarking « Magarach», 298600 Yalta, Crimea Republic
}

\begin{abstract}
The report considers the agroclimatic conditions in the Black Sea districts of cultivation and processing of grapes - the Black Sea Lowland, the Crimean Peninsula and the South-west coastal areas of the Greater Caucasus. The IRMS/SIRA techniques - Flash combustion (FC-IRMS/SIRA) \& Isotopic equilibration (EQ-IRMS/SIRA) - were first applied for the evaluation of carbon and oxygen isotopes ratios in the components of grapes from the Crimean Peninsula. The ${ }^{13} \mathrm{C} /{ }^{12} \mathrm{C}$ ratios were studied by the FCIRMS/SIRA in carbohydrates and organic acids in authentic samples of 8 grape varieties from the 2015 harvest. The EQ-IRMS/SIRA was applied to measure the ${ }^{18} \mathrm{O} /{ }^{16} \mathrm{O}$ ratios in intracellular water of grapes. The measured $\delta^{13} \mathrm{C}_{\mathrm{VPDB}}$ value ranges from -25.01 to $-21.01 \%$ (for carbohydrates), and from -25.09 to $-21.30 \%$ (for organic acids). To evaluate the extent of biological isotope fractionation the ${ }^{18} \mathrm{O} /{ }^{16} \mathrm{O}$ ratios were measured in ground water and water of atmospheric precipitates from the Crimean Peninsula. Compared to ground $\left(\delta^{18} \mathrm{O}_{\text {VSMOW }}\right.$ from -10.85 to $-8.14 \%$ ) and atmospheric (average $\delta^{18} \mathrm{O}_{\text {VSMOW }}-2.85 \%$ ) waters, the intracellular water of Crimean grape varieties is found to be enriched with ${ }^{18} \mathrm{O}$ isotope. The $\delta^{18} \mathrm{O}_{\text {vSMOw value }}$ of the grape intracellular water varies from 2.34 to $5.29 \%$ according to agroclimatic conditions of the season in 2015 .
\end{abstract}

\section{Geographical areas of the Black Sea}

The Black Sea lowland, the Crimean Peninsula and the South West Coast of Greater Caucasus form a unique cluster of a number of zones of grape cultivation, which agroclimatic conditions are influenced considerably by the Black Sea. The total length of the coastline of these three geographical areas along the Black Sea is about $1,600 \mathrm{~km}$.

The Black Sea is a closed sea of the basin of the Atlantic Ocean. The water border between Europe and Asia Minor passes on a surface of the Sea. The total area of the Black Sea makes $422,000 \mathrm{~km}^{2}$, water volume $555,000 \mathrm{~km}^{3}$ (Fig. 1).

\subsection{Black Sea Lowland}

There are 8 macrozones and 40 microzones of wine growing with a total area of vineyards of about 51,000 ha. The sum of active temperatures during the grape growing period is $2,800-3,500^{\circ} \mathrm{C}$.

The vineyards are located on normal black earth, middle- and few-humus, hard-loamy, light-clay and lightbrackish soils. The total area of the vineyards is 26,477.2 ha. A smaller number of vineyards is located on saline and micellar-carbonate soils.

The varietal composition of grapes is very diverse in this geographical area. Here grow up more than 100 vine and more than 70 table grape varieties. The most famous wine grape varieties include Rkatsiteli, Aligote, Cabernet Sauvignon, Chardonnay, Merlot, Riesling, Saperavi, Sauvignon Green, Odessa Black, Sukholimansky White etc. The known table grapes varieties are Moldova, Muscat Hamburgsky, Muscat Italia, Ranniy Magaracha, Muscat Yantarny and others [1].

\subsection{Crimean Peninsula}

The total area of the Crimean Peninsula is $27,000 \mathrm{~km}^{2}$. The main areas of cultivation of grapes are concentrated in 12 major zones, which include, for example, Western Seasidesteppe, Submontane, South Coast, Eastern Steppe and other areas. The total area of vineyards in all zones is about 31,500 ha, of which 28,000 ha are used for cultivation of wine and table grape varieties. The remaining 3,500 ha are used for varietal mixes and little-known grape varieties.

The sum of active temperatures during the grape growing period is $3,500-4,200{ }^{\circ} \mathrm{C}$. The soils, which are typical for the vineyards of the Crimean Peninsula are brown, micellar-carbonate, alluvial pratal soils, as well as the southern black and carbonate earths on eluvium and talus of carbonate rocks.

68 vine and 38 table grape varieties are grown on the Crimean Peninsula. The most common wine grape varieties include Rkatsiteli (30.3\% of vineyard's area), Cabernet Sauvignon (11.9\%), Aligote (11.1\%), Riesling (5.0\%), Bastardo Magaratchsky (4.0\%), Kokoor White $(3.7 \%)$ and others $(34 \%)$. The group of table grapes is formed by the most famous varieties - Moldova (17.7\%), Muscat Hamburgsky (13.2\%), Muscat Italia (12.8\%), Muscat Yantarny (7.9 \%), Shabash (7.8\%), Ranniy Magaracha $(6.0 \%)$. There is a number of autochthonic varieties, including Dzhevat Kara (2.3 ha total planted 


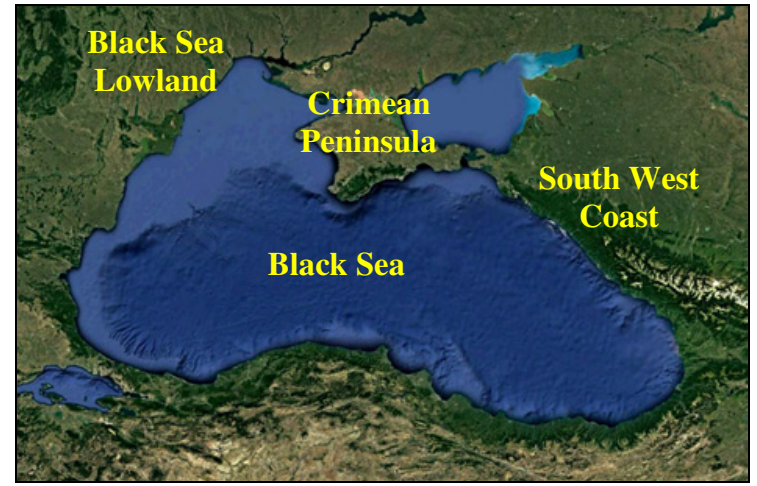

Figure 1. Geographical areas of the Black Sea.

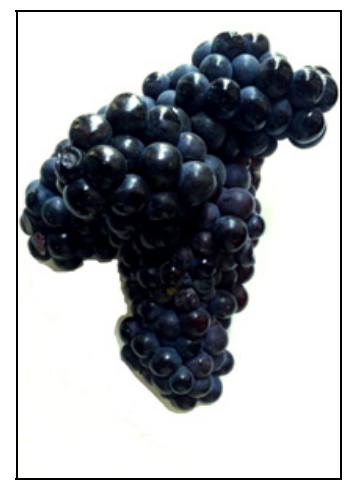

Figure 2. Autochthonic grape variety Kefessia.

area), Ekim Kara (26.6 ha), Kefessiya (55.3 ha), Kok Pandas (3.0 ha) and Kokoor White (918.3 ha) in the Crimean Peninsula [1]. The autochthonic grape variety Kefessiya is shown in Fig. 2.

\subsection{South-west coastal areas of the Greater Caucasus}

There are three main areas of viticulture in this region -Anapo-Tamansky, Southern Submontane and the Black Sea coastal areas. These zones are the leading areas of vitiand viniculture in the Krasnodar region, in which the total area of vineyards comes to 25,400 ha.

The sum of active temperatures during vegetation exceeds $3,000^{\circ} \mathrm{C}$, and in the Black Sea coastal zone even $4,000{ }^{\circ} \mathrm{C}$. Average annual precipitation ranges from 400 to $1200 \mathrm{~mm}$ with uniform distribution by seasons. The soil is heterogeneous. The vineyards are located on chestnut soils, weak-humus black earths, humus-carbonate soils, cement limestones, marl slates, sandstones, gray and brown forest soils.

Wine grape $(67 \%)$ and table grape $(33 \%)$ varieties are grown up in the region. The group of main technical varieties includes Pinot Noir, Aligote, Cabernet Sauvignon, Riesling, Saperavi, Sauvignon White, Pink Traminer and Chardonnay. The varieties of domestic selection, including Granatoviy, Teremnoy, Vostochniy, Avgaliya and Barchatniy arrange a significant proportion in the assortment of wine grapes. There is a number of famous autochthonic grape varieties - Krasnostop Zolotovskiy, Krasnostop Anapskiy and Krasnostop AZOS [2-3]. Samples of wines from domestic grapes are shown in Fig. 3.

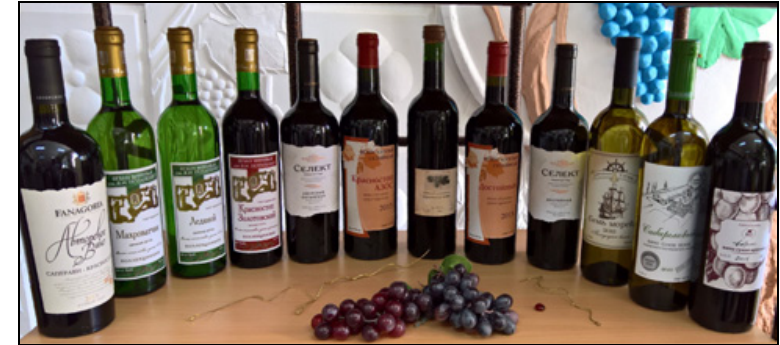

Figure 3. Wines from the domestic vine varieties (e.g. Krasnostop Zolotovskiy, Krasnostop AZOS, Amurskiy Potapenko and others).

\section{IRMS/SIRA a study of stable isotopes compositions}

Scientific study of compositions of stable isotopes of carbon $\left({ }^{13} \mathrm{C} /{ }^{12} \mathrm{C}\right)$ and oxygen $\left({ }^{18} \mathrm{O} /{ }^{16} \mathrm{O}\right)$ in components of the grapes grown in the Crimean Peninsula was conducted within the framework of the research project $^{\mathrm{b}}$ in 2015, supported by the Russian Foundation of Basic Research (RFBR). In the same project the natural fractionation of oxygen isotopes $\left({ }^{18} \mathrm{O} /{ }^{16} \mathrm{O}\right)$ was studied in waters from the underground and surface sources, as well as in water of precipitations of the Crimean Peninsula.

The studies were carried out using two types of IRMS/SIRA technique - redox transformation (Flash Combustion - FC-IRMS/SIRA) and isotopic exchange/ equilibration (Equilibration - EQ-IRMS/SIRA). Methodological principles of the FC-IRMS/SIRA and EQ-IRMSSIRA methods have been described in several publications, including OIV methods $[4,5]$.

\subsection{Materials and methods}

\subsubsection{Grape samples}

The samples of the 8 wine grape varieties were used for the study - Furmint, Muscat White, Cabernet Sauvignon, Kefessiya, Ekim Kara, Aligote, Bastardo Magarachsky and Bookovinka. The sampling of the authentic fresh grapes was carried out in 4 viticulture areas of the Crimean Peninsula - Area \# 1 (Western Maritime-Steppe area, village Romashkino), Area \# 2 (Western FoothillsMaritime area, village Uglovoye), Area \# 3 (Western zone of the South Coast area, township Aiy-Danil) and Area \# 4 (Eastern Mountain-Valleey Maritime zone of the South Coast area, village Morskoye). The geographical position of all areas are shown in Fig. 4. The total area of sampling vineyards made 571.8 ha. The sampling was conducted according to the requirements described in [1]. The weight of the average sample for each grape variety amounted not less than $20 \mathrm{~kg}$. The maximum amount of precipitations was observed in August and September 2015 in the Area \# $4(77.0 \mathrm{~mm})$, and the minimum - in the Area \# 2 $(5.2 \mathrm{~mm})$ according to the registered climate data. While the maximum temperature level was also registered in the Area \# $4\left(144.90^{\circ} \mathrm{C}\right)$, and the minimum - in the Area \# 1 $\left(139.30^{\circ} \mathrm{C}\right)$.

a IRMS/SIRA = Isotope Ratio Mass Spectrometry/Stable Isotope Ratio Analysis.

${ }^{\mathrm{b}}$ Research project \# 15-34-51208. 


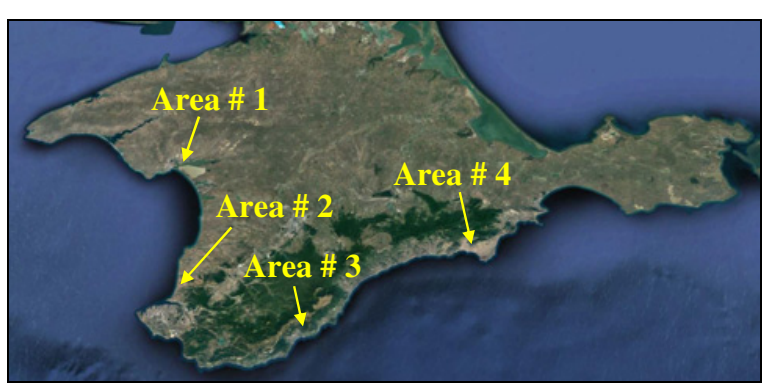

Figure 4. Grape sampling areas in the Crimean Peninsula.

The research program included 11 samples of grapes of the above stated varieties. The fresh musts were obtained under the laboratory conditions by mechanical grape crusher after stemming. The musts were used for later measurements of the composition of the carbon isotopes ${ }^{13} \mathrm{C} /{ }^{12} \mathrm{C}$ in carbohydrates (sugars) and organic acids by the FC-IRMS/SIRA method (see 2.1.3). The composition of oxygen isotopes ${ }^{18} \mathrm{O} /{ }^{16} \mathrm{O}$ was studied by the EQ-IRMS/ SIRA method directly in the musts without prior isolation of intracellular water from the samples (see 2.1.4).

Gentle conditions for the extraction of musts exclude any changes in the natural composition of carbon and oxygen isotopes in the target components of grapes carbohydrates (sugars), organic acids and intracellular water. In order to ensure the microbiological stability the musts samples have been pasteurized and filled in glass containers under aseptic conditions. Before the isotopic measurements the must samples were stored at a temperature from 2 to $4^{\circ} \mathrm{C}$ in sealed sterile glass containers without access of air.

\subsubsection{Water samples}

To study the composition of stable isotopes of oxygen $\left({ }^{18} \mathrm{O} /{ }^{16} \mathrm{O}\right) 4$ water samples were taken in three areas of the Crimean Peninsula - two samples of the tap water used for irrigation of vineyards in Areas \# 1 \& 2, one sample water from natural underground source used for irrigation of vineyards in the Area \# 3, one sample - water from atmospheric precipitations in the Area \# 3 (see Fig. 4).

The water samples were stored before the isotopic measurements at a temperature from 2 to $4{ }^{\circ} \mathrm{C}$ in sealed sterile glass containers without access of air. The study of natural fractionation of stable oxygen isotopes $\left({ }^{18} \mathrm{O} /{ }^{16} \mathrm{O}\right)$ in the surface and underground waters as well as in water of atmospheric precipitations was carried out on the basis of the RFBR the project \# 15-34-51208 for the first time in the history of meteorological observations in the Crimean Peninsula.

\subsubsection{FC-IRMSISIRA method for $\delta^{13} C_{V P D B}$ analysis}

The study of fractionation effect of the stable isotopes of carbon $\left({ }^{13} \mathrm{C} /{ }^{12} \mathrm{C}\right)$ in grape components - carbohydrates (sugars) and organic acids using the EQ-IRMS/SIRA method was carried out by using of the following laboratory facilities for stable isotopes measurements:

(A) an elemental analyzer with the combined oxidation-reduction reactor Flash $2000 \mathrm{HT}^{\circledR}$ (Thermo Fisher Scientific, Germany) and autosampler Costech ${ }^{\circledR}$ (Costech, USA);
(B) an isotopic interface ConFlo IV ${ }^{\circledR}$ (Thermo Fisher Scientific, Germany);

(C) an IRMS/SIRA isotopic mass spectrometer Delta V Advantage ${ }^{\circledR}$ (Thermo Fisher Scientific, Germany);

(D) a gas system for the supply of the analytical devices with highly purified gases Sigm-Plus ${ }^{\circledR}$ (Sigm-Plus Ltd., Russian Federation);

(E) a PC workstation Optiplex $960^{\circledR}$ (Dell, USA) for data registration and processing by the high level software Isodat 3.0 ${ }^{\circledR}$ (Thermo Fisher Scientific, Germany).

The reference substance IAEA-CH-6 (Sucrose, $\delta^{13} \mathrm{C}=$ $-10.449 \%$ ) was used for the calibration of the working reference gas (WRG) - carbon dioxide $99.9999 \%$ (Linde Gas RUS, Russian Federation). The high purity helium 99.9999\% (Linde Gas RUS, Russian Federation) was used in the study as carrier gas.

Sample preparation - extraction and purification of carbohydrates (sugars) and organic acids from musts obtained from fresh grapes - was performed according to the method described in [6]. The isolated and purified preparations of carbohydrates (sugars) and organic acids were freeze-dried at $-50^{\circ} \mathrm{C}$ in the laboratory liophile facility VaCo $2^{\circledR}$ (Zirbus Technology, Germany). The preparations were stored at a temperature no higher than $-20^{\circ} \mathrm{C}$ in a sealed glass container.

Measurements of composition of stable carbon isotopes in carbohydrates (sugars) and organic acids in prepared samples were conducted using redox transformations (flash combustion) of organic matter in elemental gases. The carbon contained in the complex organic matter is almost completely transformed into the carbon dioxide gas molecules formed during the redox reaction under extreme temperatures (e.g., $\geq 1000^{\circ} \mathrm{C}$ ) and in the presence of both bound and free molecular oxygen according to the general combustion Eq. (1):

$$
\begin{gathered}
{\left[\mathrm{C}_{n} \mathrm{H}_{x} \mathrm{O}_{y}\right]+(n+0,25 x-0,5 y) \mathrm{O}_{2}} \\
\longrightarrow n \mathrm{CO}_{2}+0,5 x \mathrm{H}_{2} \mathrm{O} .
\end{gathered}
$$

The carbon isotopes ${ }^{13} \mathrm{C} \&{ }^{12} \mathrm{C}$ which are a part of the organic matter will form the structure of the isotopomers of $\mathrm{CO}_{2}$ which are generated during the combustion. Thus, the measurement of carbon dioxide molecules with masses of 44 and 46 allows the quantification of the carbon isotopes and calculation the $\delta^{13} \mathrm{C}_{\mathrm{VPDB}}$ value, which characterize the ratio of carbon isotopes ${ }^{13} \mathrm{C}$ and ${ }^{12} \mathrm{C}$ in test sample material relative to the selected reference substance (e.g. IAEACH-6 Sucrose).

The above mentioned laboratory facilities have been used for isotope measurements. All measurements were carried out taking into account guidelines published in [4,7-9]. Joint hinges of preparations of carbohydrates (sugars) or organic acids containing from 40 to $100 \mathrm{ng}$ of carbon were placed in tin capsules before carrying out the measurements. The capsules were thoroughly covered with the help of microtweezers, providing its full integrity and eliminating the contact of organic matter with the atmospheric air. The encapsulated hinges (in five replicates for each sample) were placed into the autosampler mounted on the redox reactor of the elemental analyzer (A). Along with the hinges of carbohydrates (sugars) or organic acids the encapsulated reference substance was loaded into the autosampler for control of reliability of measurement's results. 


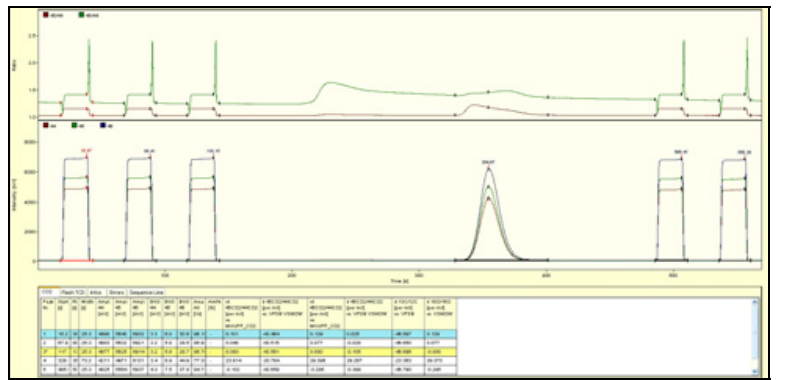

Figure 5. Typical registration module of results of the carbon isotopes ${ }^{13} \mathrm{C} /{ }^{12} \mathrm{C}$ measurement by the FC-IRMS/SIRA method.

The conditions of carring out measurements of isotope composition of carbon in the preparations of carbohydrates (sugars) and organic acids by using the stated above laboratory facilities corresponded to the optimum modes which are developed during the preliminary runs. Quantitative combustion of carbohydrates (sugars) and organic acid was performed in a helium flow (flow rate $100 \mathrm{ml} / \mathrm{min}$ ) in the redox reactor of the elemental analyzer (A) at a temperature of $1020{ }^{\circ} \mathrm{C}$ in the presence of molecular high purity oxygen $99.999 \%$ (Linde Gas RUS, Russian Federation). The separation of elementary gases resulting from the combustion of carbohydrates (sugars) or organic acids preparations in the redox reactor was carried out in automatic mode by the chromatographic purification in the elemental analyzer $(A)$. Water contained in the gas flow was removed by the trap column filled with the magnesium perchlorate.

For the quantitative measurement of carbon isotopes ${ }^{13} \mathrm{C} /{ }^{12} \mathrm{C}$, the isolated carbon dioxide is directed through isotopic interface $(B)$ to the IRMS/SIRA mass spectrometer Delta $\mathrm{V}$ Advantage ${ }^{\circledR}(C)$. Accelerating voltage of the mass spectrometer was $3.07 \mathrm{kV}$, pressure in the ion source $-1.8 \times 10^{-6} \mathrm{kPa}$, ionization method - electron impact (electron energy $124 \mathrm{eV}$ ). The IRMS/SIRA mass spectrometer Delta V Advantage ${ }^{\circledR}$ has five detectors - Faraday cups, three of them carry out simultaneous continuous monitoring of the signal $\left[\mathrm{CO}_{2}\right]^{+}$for the three major ions with masses $44\left({ }^{12} \mathrm{C}^{16} \mathrm{O}^{16} \mathrm{O}\right), 45\left({ }^{13} \mathrm{C}^{16} \mathrm{O}^{16} \mathrm{O}\right.$ and $\left.{ }^{12} \mathrm{C}^{17} \mathrm{O}^{16} \mathrm{O}\right)$ and $46\left({ }^{12} \mathrm{C}^{16} \mathrm{O}^{18} \mathrm{O},{ }^{12} \mathrm{C}^{17} \mathrm{O}^{17} \mathrm{O}\right.$ and $\left.{ }^{13} \mathrm{C}^{17} \mathrm{O}^{16} \mathrm{O}\right)$.

During the measurement cycle the WRG calibrated against a reference substance IAEA-CH-6 is introduced into the mass spectrometer - three portions WRG at the beginning of the cycle and two portions WRG at the end. Measurement of each sample was performed in five replicates. For subsequent calculation of the $\delta^{13} \mathrm{C}_{\mathrm{VPDB}}$ value $(\% 0)$, the intensities of the impulses of the carbon dioxide masses 46 and 44 should be used. Registration and processing of measurements results, as well as control for all devices of the analytical system is done via a PC workstation $(E)$. The typical registration module is shown in Fig. 5.

The calculation is based on the formula (1) and performed by the Isodat $3.0^{\circledR}$ software after registration of measurement's data:

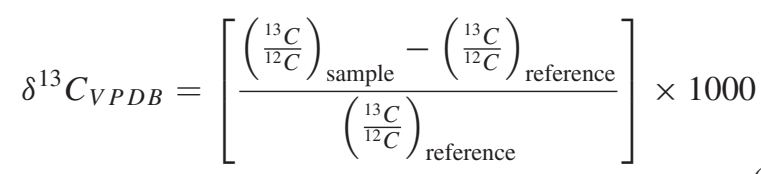

where $\left({ }^{13} \mathrm{C} /{ }^{12} \mathrm{C}\right)_{\text {sample }}$ - carbon isotopes ratio in carbohydrates (sugars) or organic acids of test samples, $\left({ }^{13} \mathrm{C} /{ }^{12} \mathrm{C}\right)_{\text {reference }}$ - carbon isotopes ratio in reference substance.

The conducting of a simultaneous correction of measured values of signal strength is an important aspect for control of accuracy of results to exclude the possible influence of isobars ${ }^{12} \mathrm{C}^{17} \mathrm{O}^{17} \mathrm{O}$ and ${ }^{13} \mathrm{C}^{17} \mathrm{O}^{16} \mathrm{O}$ which share is determined at the hardware level by the measurement of a signal of carbon dioxide of mass 45 taking into account the extent of the distribution of the isotopes ${ }^{13} \mathrm{C}$ and ${ }^{17} \mathrm{O}$ in the nature (respectively 1.11 and $0.0375 \%)$.

\subsubsection{EQ-IRMSISIRA method for $\delta^{18} O_{V S M O W}$ analysis}

The study of fractionation effect of the stable isotopes of oxygen $\left({ }^{18} \mathrm{O} /{ }^{16} \mathrm{O}\right)$ in the intracellular water in grapes (musts) and water samples (Sects. 2.1.1 \& 2.1.2) using the EQ-IRMS/SIRA method was carried out by using of the laboratory facilities for stable isotopes measurements:

(A) a module used for sample preparation for the analysis (Thermo Fisher Scientific, Germany);

(B) a control unit for chromatographic purification and samples injection Gasbench II ${ }^{\circledR}$ (Thermo Fisher Scientific, Germany);

$(C)$ an IRMS/SIRA isotopic mass spectrometer Delta V Advantage ${ }^{\circledR}$ (Thermo Fisher Scientific, Germany);

(D) a gas system for the supply of the analytical devices with highly purified gases Sigm-Plus ${ }^{\circledR}$ (Sigm-Plus Ltd., Russian Federation);

(E) a PC workstation Optiplex $960^{\circledR}$ (Dell, USA) for data registration and processing by the high level software Isodat 3.0 ${ }^{\circledR}$ (Thermo Fisher Scientific, Germany).

The reference substance IAEA-CH-6 (Sucrose, $\delta^{13} \mathrm{C}=$ $-10.449 \%$ ) was used for the calibration of the working reference gas (WRG) - carbon dioxide $99.9999 \%$ (Linde Gas RUS, Russian Federation). The additional reference substances (all from the IAEA, Austria) with known composition of oxygen isotopes ${ }^{18} \mathrm{O} /{ }^{16} \mathrm{O}$ were used for adjustment of measurement's results: VSMOW2 (Vienna-Standard Mean Ocean Water, $\delta^{18} \mathrm{O}=0.00 \%$ ); GISP (Greenland Ice Sheet Precipitation, $\delta^{18} \mathrm{O}_{\text {VSMOW }}=$ $-24.76 \%$ ); SLAP2 (Standard Light Antarctic Precipitation, $\delta^{18} \mathrm{O}_{\text {VSMOW }}=-55.50 \%$ ) .

High purity gases were used in the study - flushing gas - helium $99.9999 \%$, containing $0.4-0.5 \%$ of high purity carbon dioxide (99.9999\%), carrier gas - helium $99.9999 \%$ (all from Linde Gas RUS, Russian Federation).

Sample preparation for the direct measurement of oxygen isotopes in intracellular water was carried out by isotopic equilibration technique (EQ-IRMS/SIRA method). For isotopic equilibration reaction, $0.500 \mathrm{ml}$ of grape must or $0.200 \mathrm{ml}$ of water was added into a $12 \mathrm{ml}$ round-bottom borosilicate glass vial. The tubes were hermetically sealed by disposable screw cap with Teflonsilicone membrane. $0.200 \mathrm{ml}$ of reference substances VSMOW2, GISP and SLAP2 were added separately in similar tubes.

To carry out measurement, we formed series (groups) of tubes. Each group included the required number of sample tubes and test tubes with reference substances. A batch of tubes was placed in the cells of the sample 
preparation module $(A)$. Results of preliminary experiments on the duration of the isotopic equilibration reactions show that the equilibrium state occurs after at least 18 hours. The optimum temperature for the reaction was $24.0 \pm 0.1^{\circ} \mathrm{C}$.

The reaction of an isotopic exchange in closed systems under controlled conditions (e.g. compostion of the gas phase, temperature and duration) can be described as the following general Eq. (3):

$$
\begin{aligned}
& { }^{12} \mathrm{C}^{16} \mathrm{O}^{16} \mathrm{O}+{ }^{1} \mathrm{H}^{1} \mathrm{H}^{18} \mathrm{O} \leftrightarrow{ }^{12} \mathrm{C}^{16} \mathrm{O}^{18} \mathrm{O}+{ }^{1} H^{1} H^{16} O \\
& m=44 \quad m=20 \quad m=46 \quad m=18 .
\end{aligned}
$$

According to equation isotopic exchange occurs between the molecules of carbon dioxide contained in the closed volume of the controlled gas environment and water molecules, including molecules of the water which is a part of the studied liquid object. For example, in this system one oxygen atom with atomic mass of 16 from a carbon dioxide molecule of mass 44 is replaced with one oxygen atom with atomic mass of 18 from a water molecule when interacting in the gas phase with increasing mass of a carbon dioxide molecule up to 46. Measurement of carbon dioxide molecules with masses of 44 and 46 allows the quantification of the oxygen isotopes ${ }^{18} \mathrm{O}$ and ${ }^{16} \mathrm{O}$ and calculation of the $\delta^{18} \mathrm{O}_{\mathrm{VSMOW}}$ value for the water contained in the liquid object.

At the end of the isotope exchange reaction the gas mixture from each tube was transferred to the control unit Gasbench II ${ }^{\circledR}(B)$. Gas mixture was dried over by molecular sieve membrane Nafion ${ }^{\circledR}$ and transferred to the gas chromatograph installed in the control unit Gasbench $\mathrm{II}^{\circledR}(B)$. Chromatographic separation is carried out in helium flow $(2 \mathrm{ml} / \mathrm{min})$, column used - PLOT Fused Silica, stationary phase CP-PoraPLOT Q, length $25 \mathrm{~m}$, diameter $0.32 \mathrm{~mm}$ (Varian, USA), column temperature $70^{\circ} \mathrm{C}$. Temperature of samples in the sample module (1) was maintained at a constant level of $24.0 \pm 0.1^{\circ} \mathrm{C}$ until the end of the measurements.

Quantitative measurements of oxygen isotopes ${ }^{18} \mathrm{O} /{ }^{16} \mathrm{O}$ were performed according to conditions described above in the section 2.1.3 and in [10]. During the measurement cycle the WRG calibrated against a reference substance IAEA-CH-6 is introduced into the mass spectrometer five portions WRG at the beginning of the cycle and three portions WRG at the end. Measurement of each sample was performed in triplicate in series of 10 impulses. For subsequent calculation of the $\delta^{18} \mathrm{O}_{\text {VsMow }}$ value (\%0), the intensities of 7,8 and 9th impulses of the carbon dioxide with masses 46 and 44 should be used. Registration and processing of measurements results, as well as control for all devices of the analytical system is done via a PC workstation $(E)$. The typical registration module is shown in Fig. 6.

The results of measurements calculated according to the formula (1) on the basis of the recorded signals for the masses 44 and 46 are subjected to further adjustment. This adjustment takes into account the linear relationship between the values $\delta^{18} \mathrm{O}_{\text {VSMOW }}$ of used reference substances VSMOW2, GISP, SLAP2 and the values measured for these references in each batch of samples.

The correlation coefficient of the linear dependence must be not lower than 0.99999. Otherwise, the

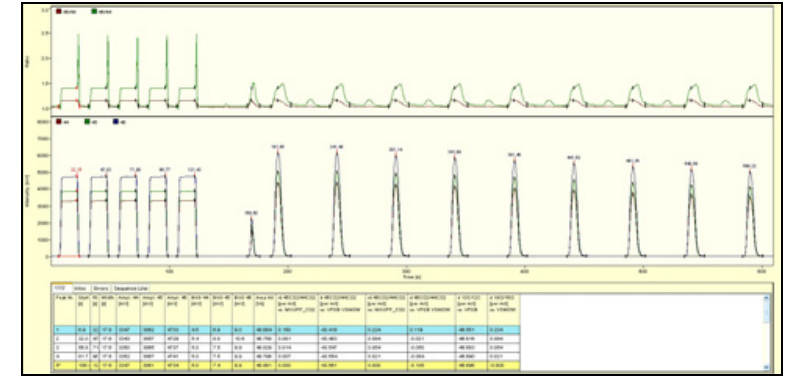

Figure 6. Typical registration module of results of the oxygen isotopes ${ }^{18} \mathrm{O} /{ }^{16} \mathrm{O}$ measurement by the EQ-IRMS/SIRA method.

measurement for a particular series of samples, including measurements of reference substance included in this batch, have to be repeated until the above conditions are met.

We should also comment on the mass balance of isotopic exchange reactions. In the methodology of the isotopic equilibration used here, the volume of gas and quantity of water-containing sample are very important, because the final result of the study - value of the $\delta^{18} \mathrm{O}$ parameter - will depend on the isotope composition in the gas and in the sample. According to the procedure, water-containing samples and gases of high purity are used to create an equilibrium system. The mixture of helium and carbon dioxide is regarded as an ideal gas. For example, if the sample volume is $1 \mathrm{ml}$, the oxygen atoms concentration in the aqueous phase is 10,000 times greater than the oxygen atoms concentration in the gas phase. This amount is more than sufficient to initiate and maintain the velocity of isotopic reaction under given conditions up to its equilibrium state, which eventually provides the equivalence of the oxygen isotopes composition of the liquid and gas phases. Thus, if a liquid sample volume used in the isotopic exchange reaction ranges from 0.200 to $1.000 \mathrm{ml}$ (e.g., $0.200 \mathrm{ml}$ in the case of the sample, which does not contain dissolved solids, such as pure water; $0.500 \mathrm{ml}$ in the case of must, juice or wine), the calculation of mass balance is not required [10].

\section{Results and discussion}

\subsection{Compositions of stable isotopes in grapes and waters of the Crimean Peninsula}

The results of measurements of isotope compositions of stable carbon \& oxygen isotopes presented as $\delta^{13} \mathrm{C}_{\mathrm{VPDB}}$ and $\delta^{18} \mathrm{O}_{\text {VSMOw }}$ values, are shown below in Tables $1-4$. The tables contain the average values obtained in a batch of five parallel determinations of carbon isotopes measurements for carbohydrates (sugars) and organic acids of each studied grape variety, as well as in a batch of three parallel determinations of oxygen isotopes measurements in the intracellular water of each grape variety and water samples from surface, atmospheric and underground sources.

The expanded measurement uncertainty (EMU) of each batch of determinations did not exceed $0.6 \%$ (for carbon isotopes) and $0.11 \%$ (for oxygen isotopes). For the calculation of the EMU the coverage factor of 2 was used that corresponds to a confidence level of $95 \%$. 
Table 1. Composition of stable carbon isotopes $\left({ }^{13} \mathrm{C} /{ }^{12} \mathrm{C}\right)$ in carbohydrates (sugars) of grape varieties from selected areas of the Crimean Peninsula (crop of 2015).

\begin{tabular}{|l|c|c|c|}
\hline Grape variety & Area $^{1}$ & $\delta^{13} \mathbf{C}_{\text {VPDB }}, \% 0$ & EMU, \%0 \\
\hline Furmint & 3 & -23.58 & 0.19 \\
\hline Musat White & 3 & -22.83 & 0.05 \\
\hline Cabernet Sauvignon & 3 & -22.24 & 0.09 \\
\hline Musat White & 1 & -24.91 & 0.10 \\
\hline Cabernet Sauvignon & 1 & -21.85 & 0.52 \\
\hline Kefessiya & 4 & -25.01 & 0.25 \\
\hline Ekim Kara & 4 & -21.01 & 0.34 \\
\hline Aligote & 2 & -25.00 & 0.15 \\
\hline Cabernet Sauvignon & 2 & -22.80 & 0.18 \\
\hline Bastardo Magarachsky & 3 & -24.78 & 0.45 \\
\hline Bookovinka & 4 & -23.92 & 0.34 \\
\hline
\end{tabular}

Notes to the Table 1:

${ }^{1}$ For area's numbers see 2.1.1 and Fig. 4.

Table 2. Composition of stable carbon isotopes $\left({ }^{13} \mathrm{C} /{ }^{12} \mathrm{C}\right)$ in organic acids of grape varieties from selected areas of the Crimean Peninsula (crop of 2015).

\begin{tabular}{|l|c|c|c|}
\hline Grape variety & Area $^{1}$ & $\delta^{13} \mathbf{C}_{\text {VPDB }}, \% 0$ & EMU, \%0 \\
\hline Furmint & 3 & -24.34 & 0.19 \\
\hline Muscat White & 3 & -22.71 & 0.32 \\
\hline Cabernet Sauvignon & 3 & -22.21 & 0.13 \\
\hline Muscat White & 1 & -24.83 & 0.15 \\
\hline Cabernet Sauvignon & 1 & -22.11 & 0.35 \\
\hline Kefessiya & 4 & -25.09 & 0.20 \\
\hline Ekim Kara & 4 & -21.30 & 0.09 \\
\hline Aligote & 2 & -24.88 & 0.05 \\
\hline Cabernet Sauvignon & 2 & -23.24 & 0.14 \\
\hline Bastardo Magarachsky & 3 & -24.66 & 0.25 \\
\hline Bookovinka & 4 & -23.99 & 0.09 \\
\hline
\end{tabular}

Notes to the Table 2:

${ }^{1}$ For area's numbers see 2.1.1 and Fig. 4.

Table 3. Composition of stable oxygen isotopes $\left({ }^{18} \mathrm{O} /{ }^{16} \mathrm{O}\right)$ in intracellular water of grape varieties from selected areas of the Crimean Peninsula (crop of 2015).

\begin{tabular}{|l|c|c|c|}
\hline Grape variety & Area $\#^{1}$ & $\delta^{\mathbf{1 8}} \mathbf{O}_{\text {vSMOw }}, \% 0$ & EMU, \%0 \\
\hline Furmint & 3 & 3.04 & 0.01 \\
\hline Musat White & 3 & 3.23 & 0.01 \\
\hline Cabernet Sauvignon & 3 & 4.21 & 0.001 \\
\hline Musat White & 1 & 4.69 & 0.01 \\
\hline Cabernet Sauvignon & 1 & 5.19 & 0.04 \\
\hline Kefessiya & 4 & 3.11 & 0.02 \\
\hline Ekim Kara & 4 & 5.29 & 0.08 \\
\hline Aligote & 2 & 2.77 & 0.02 \\
\hline Cabernet Sauvignon & 2 & 2.34 & 0.01 \\
\hline Bastardo Magarachsky & 3 & 3.31 & 0.03 \\
\hline Bookovinka & 4 & 3.89 & 0.01 \\
\hline
\end{tabular}

Notes to the Table 3:

${ }^{1}$ For area's numbers see 2.1.1 and Fig. 4.

\subsection{Conclusions}

Summarizing the data clusters obtained within the research project \# 15-34-51208 on the grape's samples taken during the harvesting period of 2015 in the Crimean Peninsula, allows to set the ranges of the natural fractionation of stable carbon and oxygen isotopes in components of
Table 4. Composition of stable oxygen isotopes $\left({ }^{18} \mathrm{O} /{ }^{16} \mathrm{O}\right)$ in water samples from selected areas of the Crimean Peninsula (study of 2015).

\begin{tabular}{|l|c|c|c|}
\hline Sample description & Area $^{\mathbf{1}}$ & $\boldsymbol{\delta}^{\mathbf{1 8}} \mathbf{O}_{\text {VSMOw }} \%$ & EMU, \%0 \\
\hline Tap water & 1 & -9.71 & 0.11 \\
\hline Tap water & 2 & -10.85 & 0.07 \\
\hline $\begin{array}{l}\text { Water of } \\
\text { atmospheric } \\
\text { precipitations }\end{array}$ & 3 & -2.85 & 0.04 \\
\hline $\begin{array}{l}\text { Water from the } \\
\text { underground } \\
\text { source }\end{array}$ & 3 & -8.14 & 0.04 \\
\hline
\end{tabular}

Notes to the Table 4:

${ }^{1}$ For area's numbers see 2.1.2 and Fig. 4.

this plant which belongs to the group of angiosperms dicotyledons of the $\mathrm{C} 3$ pathway of photosynthesis:

$\delta^{13} \mathrm{C}_{\mathrm{VPDB}}=-25.01 \ldots-21.01 \%$ (for grape's carbohydrates (sugars));

$\delta^{13} \mathrm{C}_{\mathrm{VPDB}}=-25.09 \ldots-21.30 \%$ (for grape's organic acids);

$\delta^{18} \mathrm{O}_{\mathrm{vsMOW}}=2.34 \ldots 5.29 \%$ (for grape's intracellular water).

The results of our research characterizing the fractionation of carbon isotopes in native carbohydrates (sugars) and organic acids and also oxygen isotopes in intracellular water correlate well with the published data of other researches of stable isotopes compositions in components of grapes and products of its processing (e.g., wines), which were conducted in other geographical regions with similar agroclimatic conditions, including the sum of active temperatures from 3500 to $4500^{\circ} \mathrm{C}$ $\left(>10^{\circ} \mathrm{C}\right)$, an amount of precipitation from 200 to 900 $\mathrm{mm}$, frequent water deficiency and an irregular irrigation (or total absence of that) during the vegetative period. For example, it was shown that the carbohydrates (sugars) of grapes which are grown up in the conditions of water deficiency and high level of active temperatures are enriched by "heavy" ${ }^{13} \mathrm{C}$ carbon isotopes. In this case the $\delta^{13} \mathrm{C}_{\mathrm{VPDB}}$ reaches maximum values from $-21,0$ to $-20,0 \%$ [11-13]. In our study the width of the range of values for natural carbohydrates (sugars) in 8 grape varieties amounts to $4 \%$.

The results obtained for grapes from the sampling Areas \# 1 \& 2 (Fig. 4) of the Crimean Peninsula, which show a significant difference of $55 \%$ in fractionation of oxygen isotopes in the intracellular water between $\delta^{18} \mathrm{O}_{\text {VSMOW }}$ values, can represent a certain scientific basis for planning and carrying out further work to supplement the available experimental data. Carbohydrates (sugars) and organic acids of grape varieties from the Crimean Peninsula regarding the carbon isotope composition are almost equivalent in accordance with the experimental data from this study, taking into account the quantitative levels of measurement uncertainty. In this part the results of the study correlate well with published data from other scientific researches. For example, according to [14], the difference between the $\delta^{13} \mathrm{C}_{\mathrm{VPDB}}$ values for sugars and acids from the C3-plants ranges from -1.5 to $0.5 \%$.

The experimental data about fractionation of stable oxygen isotopes in water of three areas in the Crimean Peninsula (Western Maritime-Steppe area, 
Western Foothills-Maritime area, Western zone of the South Coast area) are first obtained within a scientific study. The research results for three samples show the $\delta^{18} \mathrm{O}_{\text {Vsmow }}$ values, which are characteristic for the natural fractionation of oxygen isotopes in the geological underground waters. The obtained research data can be used for an assessment of influence of technogenic factors (e.g., use of water in wine production) on the quantitative level of $\delta^{18} \mathrm{O}_{\text {vSMOW }}$ in commercial products. For example, the extension of wine with water will lead to a general decrease in the quantity of "heavy" oxygen ${ }^{18} \mathrm{O}$ isotope and, consequently, to a decrease in the $\delta^{18} \mathrm{O}_{\mathrm{VSMOW}}$ level.

The average value of measured $\delta^{18} \mathrm{O}_{\text {VSMow }}$ in one water sample of the atmospheric precipitations from the Western zone of the South Coast area in the Crimean Peninsula was equal to $-2.85 \%$. This is consistent with the fundamental regularities of the fractionation of oxygen and hydrogen isotopes in water cycle in coastal tropics and subtropics areas of seas and oceans. Concerning levels for so-called "Standard Mean Ocean Water" $\left(\delta^{18} \mathrm{O}=0 \%\right.$, $\delta \mathrm{D}\left({ }^{2} \mathrm{H}\right)=0 \%$ ) the theoretically possible values for $\delta^{18} \mathrm{O}_{\text {VSMow }}$ (oxygen) and $\delta \mathrm{D}\left({ }^{2} \mathrm{H}\right)_{\text {VSMOW }}$ (hydrogen) of atmospheric water in coastal zones will amount to -3.0 and $-14.0 \%$ respectively. On the basis of the experimental $\delta^{18} \mathrm{O}_{\text {vSMOW }}$ level for the sample of the atmospheric water from our study the $\delta \mathrm{D}\left({ }^{2} \mathrm{H}\right)_{\text {VSMOw }}$ value can be calculated by using of the specified Craig's equation [15], which will amount to $-12.37 \%$. Thus, water of the atmospheric precipitations in the Western zone of the South Coast area of the Crimean Peninsula match the level of enrichment of water's molecules with the "heavy" oxygen isotope ${ }^{18} \mathrm{O}$, which is typical for the coasts of seas and oceans.

The results of the study can be used in practice for quality assessment, including identification of commercial products offered on national and international foodstuffs markets, for example, wines from the regions with a Geographical Indication (GI) or Designation of Origin (DO). This assessment using IRMS/SIRA stable isotope technique can be carried out within the existing systems for evaluation of the quality of products for the detection of adulterations. The evaluation of the isotopic composition of carbon and oxygen can support the analytical determination of the geographical origin of products, which has practical importance for international trade. However, in applying the results of this study, including above shown intervals of $\delta^{13} \mathrm{C}_{\mathrm{VPDB}}$ and $\delta^{18} \mathrm{O}_{\mathrm{VSMOW}}$ for grapes from the Crimean Peninsula, for example, when planning a scientific or an applied work, it is necessary to take into account interrelations of the obtained experimental data with agroclimatic conditions of cultivation and harvest of 2015, and also to consider the size of a data matrix which is defined by a quantity of samples, climate peculiarities sampling areas and grape varieties.
Studies of biological fractionation of stable isotopes of light elements in components of grapes from the Crimean Peninsula, South West Coast of the Greater Caucasus and other vine growing regions will be continued on the basis of ongoing basic and applied research programs.

The authors thank the Russian Foundation of Basic Research for support of this IRMS/SIRA study, Wine-growers and Wineries from the Crimean Peninsula for assistance with sampling of authentic grapes, Colleagues from the Magarach Institute for their enthusiastic support of this research.

\section{References}

[1] Г. Технология виноградных вин (Таврида, Симферополь, 2001) / G. Valuyko, Technology of grape wines (Tavrida, Simferopol, 2001)

[2] Electronic data on viti- and viniculture in the Krasnodar region available online at the http://www.vitis.ru, last accessed on September, 012016

[3] Государственный реестр охраняемых селекционных достижений (ФГБНУ «Росинформагротех», Москва, 2016) / State Register of Protected Selection Achievements (FGBNU «Rosinformagrotekh», Moscow, 2016)

[4] Method OIV-MA-AS312-06 (2001)

[5] Method OIV-MA-AS2-12 (2009)

[6] BS DD ENV 12140:1997-02-15 (1997)

[7] А. Колеснов, И.Филатова, О. Малошитская, М. Зенина, И. Питрюк, Напої. Технології та Інновації 10, 48-51 (2015) / А. Kolesnov, I. Filatova, O. Maloshitskaya, M. Zenina, I. Pitruyk, Beverages. Technologies \& Innovations 10, 48-51 (2015)

[8] А. Колеснов, И. Филатова, О. Малошицкая, М. Зенина, И. Питрюк, Напої. Технологіi та Інноваці 11, 54-57 (2015) / A. Kolesnov, I. Filatova, O. Maloshitskaya, M. Zenina, I. Pitruyk, Beverages. Technologies \& Innovations 11, 54-57 (2015)

[9] Finnigan Elemental Analyzer. Operating Manual (Thermo Electron Corporation, Carbon Measurement, 5-1...5-20, 2010)

[10] Gasbench II. Operating manual (Thermo Fisher Scientific, Revision A-1118343: 5-33-5-39, 5-42, 2009)

[11] J.-P. Gaudillere, C. Van Leeuwen, N. Ollat, J. Exp. Bot. 53, 757-763 (2002)

[12] S. Gomez-Alonso, E. Garcia-Romero, Aust. J. Grape Wine Res. 16, 283-289 (2010)

[13] N. Christoph, BIO Web of Conferences 5, 02020 (2015)

[14] Code of practice of the European Fruit Juice Association (2014)

[15] H. Craig, Science 133, 1702-1703 (1961) 